\title{
Persistence of the isotopic signature of pentavalent uranium in magnetite
}

Zezhen Pan; ${ }^{1,2}$ Yvonne Roebbert; ${ }^{3}$ Aaron Beck; ${ }^{4}$ Barbora Bartova; ${ }^{2}$ Tonya Vitova; ${ }^{4}$ Stefan

Weyer; ${ }^{3}$ Rizlan Bernier-Latmani ${ }^{2, *}$

${ }^{1}$ Department of Environmental Science and Engineering, Cluster of Interfacial Processes Against Pollution (CIPAP), Fudan University, Shanghai, 200438, China

2 École polytechnique fédérale de Lausanne, Environmental Microbiology Laboratory, Lausanne, 1015 , Switzerland

${ }^{3}$ Institut für Mineralogie, Leibniz, Universitat Hannover, D-30167 Hannover, Germany

${ }^{4}$ Institute for Nuclear Waste Disposal (INE), Karlsruhe Institute of Technology, Karlsruhe 76021, Germany

Environmental Science \& Technology

SI content:

Text S1 U isotope analysis by MC-ICP-MS

Text 2 M4-edge HERFD-XANES measurement

Text S3 Preparation of TEM samples

Text S4 Calculation on the $\delta^{238} \mathrm{U}$ of U(IV) species in U-mag-HCl-aq

Table S1 Percent of total U removed from U-mag with $50 \mathrm{mM}$ bicarbonate and the corresponding isotope signatures

Table S2 Percent of total $U$ and Fe removed by the extraction of $U$-mag suspensions by variable $\mathrm{HCl}$ concentrations

Table S3 LCF of the M4-edge HERFD-XANES spectra

Table S4 Mass percentage of $U$ in the extracted aqueous phase or solid phase and corresponding $\delta^{238} \mathrm{U}$ values, for the $U$-mag-doped and $U$-mag-oxidized systems

Figure S1 XRD spectra of U-mag, U-mag-HCl, U-mag-doped

Figure $\mathrm{S} 2 \quad \mathrm{~L}_{3}$-edge XAS spectra of $U$-mag, $U$-mag- $\mathrm{HCl}$

Figure S3 U distribution between solid and aqueous phase after bicarbonate or $\mathrm{HCl}$ extraction

Figure S4 U M4-edge HERFD XANES spectra of solid phase samples

Figure S5 HAADF STEM images of sample U-mag, U-mag-HCl, U-magdoped and U-mag-oxidized. 


\section{Text S1}

Sample preparation for $\mathbf{U}$ isotopic analysis. Samples were evaporated to dryness and treated with a mixture of $200 \mu \mathrm{L} \mathrm{14M} \mathrm{HNO} 3$ and $200 \mu \mathrm{L} \mathrm{H}_{2} \mathrm{O}_{2}$ (30\%). Uranium was purified on Eichrom UTEVA resin using the ion-exchange chromatographic method based on Weyer et al. $(2008)^{2}$. Prior to resin separation, samples were dissolved in $3 \mathrm{M} \mathrm{HNO}_{3}$ and spiked with a weighted aliquot of the ${ }^{236} \mathrm{U} /{ }^{233} \mathrm{U}$ isotope tracer (IRMM 3636-A, ${ }^{236} \mathrm{U} /{ }^{233} \mathrm{U}=0.98130$ ) to correct for potential isotope fractionation during $\mathrm{U}$ separation and instrumental mass discrimination during isotope measurements.

U isotope analysis by MC-ICP-MS. Samples were introduced with a Cetac Aridus-II in combination with a $100 \mu 1$ PFA nebulizer, a standard Ni sampler cone, a Ni X skimmer cone and a $0.8 \mathrm{~mm}$ copper ring (spacer) were used. The samples were diluted to concentrations of $70 \mathrm{ppb}$ and with this setup a signal of $\sim 90 \mathrm{~V}$ was achieved for ${ }^{238} \mathrm{U}$. All samples were measured in 60 cycles (with an integration time of 4 seconds). The samples were measured with standard sample bracketing (i.e., every two samples were bracketed by an IRMM-184 standard).

Three replicate analyses were performed for each sample. The precision is reported as two standard deviations ( 2 S.D.) of the replicate analyses for each sample, which is typically $\leqslant 0.1 \%$. Analytical quality, i.e., the accuracy of the analytical protocol, has been tested frequently by replicate analyses of the U standards REIMEP 18-A and IRMM-184 relative to CRM-112A and results agreed (within uncertainties) with those previously reported in the literature ${ }^{1-4}$.

\section{$\underline{\text { Text S2 }}$}

M4-edge HERFD-XANES measurement: Wet pastes were mounted onto depressions (1-3 mm thick) within plexiglass plates that were sealed with a layer of $8 \mu \mathrm{m}$-thick Kapton film. Sealed plexiglass plates were immediately frozen inside a liquid-nitrogen cooled cold well inside the anoxic chamber to minimize any change in the samples. Sealed frozen samples were then stored in the freezer $\left(-20^{\circ} \mathrm{C}\right)$ inside the anoxic chamber until transport to beamlines. Each plexiglass plate was sealed within two layers of mylar before being placed in a hermetically sealed stainless-steel shipping anoxic canister (Schuett-Biotec GmbH, Göttingen, Germany) to be shipped to the KIT synchrotron radiation facility. The canister was placed in dry ice during transport to keep samples frozen. Sample plates were placed in a sample cell, serving as second containment, with a window that was covered by a layer of $13 \mu \mathrm{m}$ Kapton film. The incident energy was selected using a Si(111) double crystal monochromator (DCM) and focused to a size of $\sim 0.5 \times 0.5 \mathrm{~mm}$ onto the sample. Sample, four crystal analysers and a single diode VITUS silicon drift detector (VITUS SDD KETEK) were arranged in a vertical Rowland geometry, completely contained within a plexiglass glovebox continuously flushed with $\mathrm{He}$, maintaining a $\mathrm{He}$ atmosphere $(99.5 \% \mathrm{He})$ in order to minimize scattering and absorption of the photons in the tender X-ray regime. The He atmosphere was monitored indirectly by continuous observation of the $\mathrm{O}_{2}$ level. The sample cell was flushed by a separate He flow in order to avoid 
oxidation of the samples by traces of oxygen in the box. The HERFD-XANES spectra were obtained by recording the maximum intensity of the $\mathrm{M}_{\beta}$ emission line, diffracted by the four spherically bent $\mathrm{Si}(220)$ crystal analysers (SAINT-GOBAIN) with $1 \mathrm{~m}$ bending radius and focused onto a single diode VITUS SDD. The crystals were aligned at $75.36^{\circ}$ Bragg angle, corresponding to the maximum of the $\mathrm{U} \mathrm{M}_{\beta}$ fluorescence line at 3,337 $\mathrm{eV}^{5}$. The DCM was calibrated by assigning 3,725.5 eV to the maximum of the main absorption maximum ("white line", WL) of the $\mathrm{U} \mathrm{M}_{4}$-edge HERFD-XANES spectrum of a $\mathrm{UO}_{2}$ sample. Three to five scans were collected and averaged per sample, each of them on a different spot in order to avoid beam-induced changes within the sample.

Spectral analysis: Spectral analysis was performed by iterative transformation factor analysis (ITFA) $)^{6,7}$ to determine the proportion of $\mathrm{U}(\mathrm{IV}), \mathrm{U}(\mathrm{V})$, and $\mathrm{U}(\mathrm{VI})$ in solid phase samples ${ }^{8}$. Additionally, linear combination fits (LCF) of the $\mathrm{M}_{4}$-edge spectra were performed using the ATHENA software ${ }^{9}$.

\section{$\underline{\text { Text S3 }}$}

Preparation of TEM samples: To prepare for transmission electron microscopy (TEM) analysis, solids collected by magnet separation were resuspended in $75 \%$ ethanol and sonicated for $3 \mathrm{~min}$ and a few droplets placed on a copper grid under anoxic conditions. Prepared grids were stored anoxically in a desiccator before the measurement with a double-aberration corrected Titan 60-300 transmission electron microscope (Thermo-Fisher Scientific ${ }^{\mathrm{TM}}$ ) operated at $300 \mathrm{keV}$ with $\sim 80 \mathrm{pA}$ beam current.

\section{Text S4}

\section{Calculation on the $\delta^{238} U$ of $U(I V)$ species in $U$-mag-HCl-aq.}

Though the amount of $U(V)$ released during the magnetite surface dissolution remains unknown, we attempted to estimate the $\boldsymbol{\delta}^{238} \mathrm{U}$ of U(IV) species in U-mag-HCl-aq. To do so, we assume that all U(VI) and $\mathrm{U}(\mathrm{IV})$ were released into the $\mathrm{HCl}$ leachate and that no $\mathrm{U}(\mathrm{V})$ was released. Thus, the following equation was obtained:

percent of total $\mathrm{U}$ that is $\mathrm{U}(\mathrm{VI}) \times \boldsymbol{\delta}^{238} \mathrm{U}(\mathrm{U}(\mathrm{VI}))+$ percent of total $\mathrm{U}$ that is $\mathrm{U}(\mathrm{IV}) \times \boldsymbol{\delta}^{238} \mathrm{U}(\mathrm{U}(\mathrm{IV}))=$ percent of total $\mathrm{U}$ in $\mathrm{HCl}$-leachate $\times \boldsymbol{\delta}^{238} \mathrm{U}(\mathrm{U}$ in $\mathrm{HCl}$-leachate)

Using the numbers in Table 2:

$1.2 \% \times(-0.68 \pm 0.01 \%)+(17.7 \%-1.2 \%) \times \boldsymbol{\delta}^{238} \mathrm{U}(\mathrm{U}(\mathrm{IV}))=17.7 \% \times(0.34 \pm 0.01 \% 0)$

Thus, $\boldsymbol{\delta}^{238} \mathrm{U}(\mathrm{U}(\mathrm{IV}))=0.41 \pm 0.01 \%$. 
Table S1. Percent of total U removed from duplicate U(VI)-magnetite coprecipitated solids (U-mag) with a $50 \mathrm{mM}$ bicarbonate solution (final concentration) and the corresponding isotope signatures in either the extracted aqueous phase or the remaining solid phase.

\begin{tabular}{|c|c|c|c|c|}
\hline & \multicolumn{2}{|c|}{ U-mag Replicate 1} & \multicolumn{2}{|c|}{$U$-mag Replicate 2} \\
\hline & \multicolumn{4}{|c|}{$50 \mathrm{mM}$ bicarbonate extraction } \\
\hline & $\%$ of $U$ & $\boldsymbol{\delta}^{238} \mathrm{U} \% 0$ & $\%$ of $U$ & $\boldsymbol{\delta}^{238} \mathrm{U} \%$ \\
\hline Aqueous (U-mag-bic-aq) & $0.6 \%$ & $-0.82 \pm 0.04$ & $0.4 \%$ & $-1.11 \pm 0.05$ \\
\hline Solid (U-mag-bic) & $99.4 \%$ & $-0.01 \pm 0.03$ & $99.6 \%$ & $-0.01 \pm 0.15$ \\
\hline
\end{tabular}

Table S2. Percent of total $U$ and Fe removed by the extraction of $U$-mag suspensions by variable $\mathrm{HCl}$ concentrations $(1.5,2$, and $2.5 \mathrm{mM} \mathrm{HCl})$.

\begin{tabular}{c|cc|cc}
\hline & \multicolumn{2}{|c|}{$U$-mag } & Replicate 1 & \multicolumn{2}{c}{$U$-mag Replicate 2 } \\
$\mathrm{HCl}(\mathrm{mM})$ & $\mathrm{U}(\%)$ & $\mathrm{Fe}(\%)$ & $\mathrm{U}(\%)$ & $\mathrm{Fe}(\%)$ \\
\hline 1.5 & 0.3 & 6.1 & 0.3 & 6.4 \\
2 & 2.0 & 8.1 & 0.7 & 8.3 \\
2.5 & 17.7 & 9.6 & 18.9 & 10.2 \\
\hline
\end{tabular}

Table S3. LCF of the $\mathrm{M}_{4}$-edge HERFD-XANES spectra with $\mathrm{UO}_{2}, \mathrm{BiUO}_{4}{ }^{10}$ and uranyl-acetate as references. The results were presented as supportive indicators to the results of the ITFA analysis on the composition of $U$ valence state. The error values are derived from the linear combination fit algorithm.

\begin{tabular}{llllll}
\hline Sample & $\mathrm{U}(\mathrm{IV}) \%$ & $\mathrm{BiUO}_{4} \%$ & $\mathrm{U}(\mathrm{VI}) \%$ & $\mathrm{R}$ factor & Reduced $\chi^{2}$ \\
\hline U-mag & $8.9 \pm 2.1$ & $86.6 \pm 4.8$ & $4.5 \pm 6.2$ & 0.0323 & 0.0017 \\
U-mag-bic & $9.1 \pm 1.6$ & $90.9 \pm 3.1$ & - & 0.0243 & 0.0015 \\
U-mag-HCl & - & $90.8 \pm 2.2$ & $9.2 \pm 1.9$ & 0.0109 & 0.0006 \\
U-mag-HCl-2 & - & $91.4 \pm 2.9$ & $8.6 \pm 2.9$ & 0.0246 & 0.0015 \\
\hline
\end{tabular}

\begin{tabular}{llllll}
\hline Sample & $\mathrm{U}(\mathrm{IV}) \%$ & $\mathrm{U}$-mag-HCl-2 $\%$ & $\mathrm{U}(\mathrm{VI}) \%$ & $\mathrm{R}$ factor & Reduced $\chi^{2}$ \\
\hline U-mag-doped & $51.9 \pm 2.8$ & $48.1 \pm 8.6$ & - & 0.0654 & 0.0053 \\
U-mag-doped-HCl & $0.0 \pm 1.0$ & $100.0 \pm 0.3$ & - & 0.0012 & 0.0001 \\
U-mag-oxidized & - & $53.8 \pm 4.0$ & $46.2 \pm 3.0$ & 0.0251 & 0.0016 \\
U-mag-oxidized-HCl & - & $67.7 \pm 2.1$ & $32.3 \pm 4.4$ & 0.0134 & 0.0008 \\
\hline
\end{tabular}


Table S4. Mass percentage of $U$ in the extracted aqueous phase or solid phase, corresponding $\delta^{238} \mathrm{U}$ values, and the standard deviation (s.d.) derived from duplicate measurements for each sample for the experimental data presented in Figure $3\left(\delta^{238} \mathrm{U}\right.$ and standard deviation values) and Figure S2 (mass percentages of $U$ ).

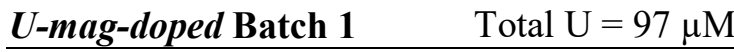

\begin{tabular}{lccc}
\hline time & \multicolumn{3}{c}{ U-mag-doped-HCl-aq } \\
\hline \multirow{2}{*}{$\mathrm{h}$} & Mass percent (\%) & $\delta^{238} \mathrm{U}[\% \mathrm{o}]$ & 2 s.d. \\
0.5 month & $55.4 \%$ & $3.8^{\mathrm{a}}$ & \\
1 month & $63.1 \%$ & 3.02 & 0.03 \\
2 months & $61.3 \%$ & 2.99 & 0.02 \\
6 months & $61.4 \%$ & 3.00 & 0.01 \\
\hline \multicolumn{4}{c}{$U$-mag-doped-HCl } \\
\hline \multicolumn{4}{c}{0.02} \\
0 h & Mass percent (\%) & $\delta^{238} \mathrm{U}[\%]$ & $2 \mathrm{~s} . \mathrm{d}$. \\
0.5 month & $44.6 \%$ & -0.11 & 0.06 \\
1 month & $36.9 \%$ & 0.51 & 0.04 \\
2 months & $38.7 \%$ & 0.88 & 0.03 \\
6 months & $38.6 \%$ & 1.08 & 0.02 \\
\hline
\end{tabular}

U-mag-doped Batch $2 \quad$ Total $\mathrm{U}=95 \mu \mathrm{M}$

\begin{tabular}{|c|c|c|c|}
\hline & \multicolumn{3}{|c|}{ U-mag-doped-HCl-aq } \\
\hline & Mass percent (\%) & $\delta^{238} \mathrm{U}[\% \mathrm{o}]$ & 2s.d. \\
\hline $0 \mathrm{~h}$ & & $\sim 3.4^{\mathrm{b}}$ & \\
\hline 0.5 month & $62.7 \%$ & 2.41 & 0.00 \\
\hline 1 month & $60.2 \%$ & 2.38 & 0.02 \\
\hline 2 months & $73.9 \%$ & 2.34 & 0.03 \\
\hline \multirow[t]{3}{*}{6 months } & $63.8 \%$ & 2.33 & 0.05 \\
\hline & \multicolumn{3}{|c|}{ U-mag-doped-HCl } \\
\hline & Mass percent (\%) & $\delta^{238} \mathrm{U}[\% 0]$ & 2s.d. \\
\hline $0 \mathrm{~h}$ & & -0.11 & 0.06 \\
\hline 0.5 month & $37.3 \%$ & 0.30 & 0.04 \\
\hline 1 month & $39.8 \%$ & 0.62 & 0.03 \\
\hline 2 months & $26.1 \%$ & 0.89 & 0.04 \\
\hline 6 months & $36.2 \%$ & 1.39 & 0.05 \\
\hline
\end{tabular}

U-mag-oxidized $\quad$ Total $\mathrm{U}=203 \mathrm{uM}$

\begin{tabular}{lccc}
\hline & \multicolumn{3}{c}{ U-mag-oxidized-HCl/bic-aq } \\
\hline & Mass percent (\%) & $\delta^{238} \mathrm{U}[\% \mathrm{o}]$ & 2 s.d. \\
2 weeks-Bic-aq & $23.5 \%$ & 0.11 & 0.02 \\
2 weeks-HCl-aq-extraction 1 & $24.3 \%$ & 0.08 & 0.03 \\
2 weeks-HCl-aq-extraction 2 & $24.9 \%$ & 0.11 & 0.02 \\
1 month-Bic-aq & $25.0 \%$ & 0.10 & 0.02
\end{tabular}




\begin{tabular}{|c|c|c|c|}
\hline 1 month-HCl-aq-extraction 1 & $30.9 \%$ & 0.09 & 0.03 \\
\hline 1 month-HCl-aq-extraction 2 & $31.9 \%$ & 0.07 & 0.03 \\
\hline 2 month-Bic-aq & $25.5 \%$ & 0.08 & 0.01 \\
\hline 2 month-HCl-aq-extraction 1 & $25.3 \%$ & 0.08 & 0.02 \\
\hline 2 month-HCl-aq-extraction 2 & $24.8 \%$ & 0.07 & 0.01 \\
\hline 6 month-Bic-aq & $29.7 \%$ & 0.12 & 0.04 \\
\hline 6 month-HCl-aq-extraction 1 & $30.7 \%$ & 0.06 & 0.05 \\
\hline \multirow[t]{3}{*}{6 month-HCl-aq-extraction 2} & - & - & - \\
\hline & \multicolumn{3}{|c|}{ U-mag-oxidized-HCl/bic } \\
\hline & Mass percent $(\%)$ & $\delta^{238} \mathrm{U}[\% 0]$ & 2s.d. \\
\hline 2 weeks-Bic & $76.5 \%$ & -0.08 & 0.04 \\
\hline 2 weeks-HCl-extraction 1 & $75.7 \%$ & -0.08 & 0.03 \\
\hline 2 weeks-HCl-extraction 2 & $75.1 \%$ & -0.08 & 0.04 \\
\hline 1 month-Bic & $75.0 \%$ & -0.05 & 0.01 \\
\hline 1 month-HCl-extraction 1 & $69.1 \%$ & -0.06 & 0.04 \\
\hline 1 month-HCl-extraction 2 & $68.1 \%$ & -0.07 & 0.02 \\
\hline 2 month-Bic & $74.5 \%$ & -0.07 & 0.01 \\
\hline 2 month-HCl-extraction 1 & $74.7 \%$ & -0.05 & 0.03 \\
\hline 2 month-HCl-extraction 2 & $75.2 \%$ & -0.04 & 0.02 \\
\hline 6 month-Bic & $70.3 \%$ & -0.07 & 0.06 \\
\hline 6 month-HCl-extraction 1 & $69.4 \%$ & -0.05 & 0.05 \\
\hline 6 month-HCl-extraction 2 & - & -0.05 & 0.03 \\
\hline
\end{tabular}

${ }^{\mathrm{a}}$ and ${ }^{\mathrm{b}}$ : $\mathrm{No} \mathrm{HCl}$ extraction of the $U$-mag-doped system was performed at time zero when the heavy isotope was introduced. Thus, the isotope signature of the extracted aqueous phase was not available. However, according to isotopic mass balance, the $\delta^{238} \mathrm{U}$ in U-mag-doped-HCl-aq phase could be calculated at various time points based on the following equation:

fraction(U-mag-doped-HCl-aq $(\mathrm{t}=0)) * \delta^{238} \mathrm{U}_{\mathrm{U}-\text { mag-doped-HCl-aq }(\mathrm{t}=0)}$

+ fraction $(U$-mag-doped-HCl$(\mathrm{t}=0)) * \delta^{238} \mathrm{U}_{U \text {-mag-doped-HCl(t=0) }}=$

fraction(U-mag-doped-HCl-aq $(\mathrm{t})) * \delta^{238} \mathrm{U}_{\mathrm{U}-\text { mag-doped-HCl-aq (t) }}$

+ fraction $(U$-mag-doped-HCl $(\mathrm{t})) * \delta^{238} \mathrm{U}_{U-\text { mag-doped-HCl(t) }}$

For instance, fraction $(U-m a g)$ represents the fraction of total $U$ that is contained within the solid phase of the $U$-mag suspension.

In order to back-calculate the $\delta^{238} \mathrm{U}$ value for extracted aqueous phase of U-mag-doped system at time zero $\left(\delta^{238} \mathrm{U}_{\mathrm{U}-\text { mag-doped-HCl-aq }(\mathrm{t}=0)}\right)$, we used the measured $\delta^{238} \mathrm{U}$ values for the solid phase and the aqueous phase at 2 months, the fraction of $U$ in the solid phase and the measured $\delta^{238} U$ value for the starting solid.

Based on $\mathrm{M}_{4}$-edge HERFD XANES measurement for $U$-mag, $78 \%$ of $U$ was characterized as an incorporated $\mathrm{U}(\mathrm{V})$ species (Table 1), while the wet chemistry results (Table 2) indicated that incorporated $U$ represented $82.3 \%$ of total $U$ and exhibited a $\delta^{238} U$ value of $-0.11 \% 00.06$ (measured for the $U-m a g-H C l$ solid phase). Thus, we averaged those two measurements of the contribution of incorporated $\mathrm{U}(\mathrm{V})$ to the total $\mathrm{U}$ and attributed $80 \%$ of the $\mathrm{U}$ to the solid phase of $U$-mag. Upon addition of the heavy U(VI) to U-mag, we doubled the overall amount of $U$. Thus, the amount of U in U-mag 
represents half of the total $\mathrm{U}$. Consequently, at time zero, $\mathrm{U}$ incorporated in the magnetite matrix represents $50 \%$ of the total $U$ and has an isotope signature of $-0.11 \% \pm 0.06$.

Thus, we applied the following values in the equation above:

fraction $\left(U\right.$-mag-doped- $\left.H C l_{(t=0)}\right)=$ average $(78 \%, 82.3 \%) * 50 \%=80 \% * 50 \%$

$\delta^{238} \mathrm{U}_{U \text {-mag-doped-HCl }(\mathrm{t}=0)}=-0.11 \% 0 \pm 0.06$

fraction (U-mag-doped-HCl-aq $(\mathrm{t}=0))=1$-fraction $\left(U\right.$-mag-doped- $\left.H C l_{(t=0)}\right)$

fraction (U-mag-doped-HCl-aq $(2$ months) $)=61.3 \%$

$\delta^{238} \mathrm{U}_{\mathrm{U} \text {-mag-doped-HCl-aq (2 months) }}=2.99 \%$

fraction $\left(U\right.$-mag-doped $\left.-\mathrm{HCl}_{(2 \mathrm{months})}\right)=38.7 \%$

$\delta^{238} \mathrm{U}_{U-\text { mag-doped-HCl(2 months })}=1.08 \%$

$(1-50 \% * 80 \%) *\left(\delta^{238} \mathrm{U}_{\mathrm{U}-\mathrm{mag} \text {-doped-HCl-aq }(\mathrm{t}=0)}\right)+(50 \% * 80 \%) *(-0.11 \pm 0.06 \% \mathrm{o})=$ $61.3 \% * 2.99 \%+38.7 \% * 1.08 \%$

Thus, $\delta^{238} \mathrm{U}_{\mathrm{U} \text {-mag-doped-HCl-aq (t }=0)}$ was calculated to be $\sim 3.8 \%$ for replicate 1 . The same procedure was carried out for replicate 2 resulting in a value of $\sim 3.4 \%$. 


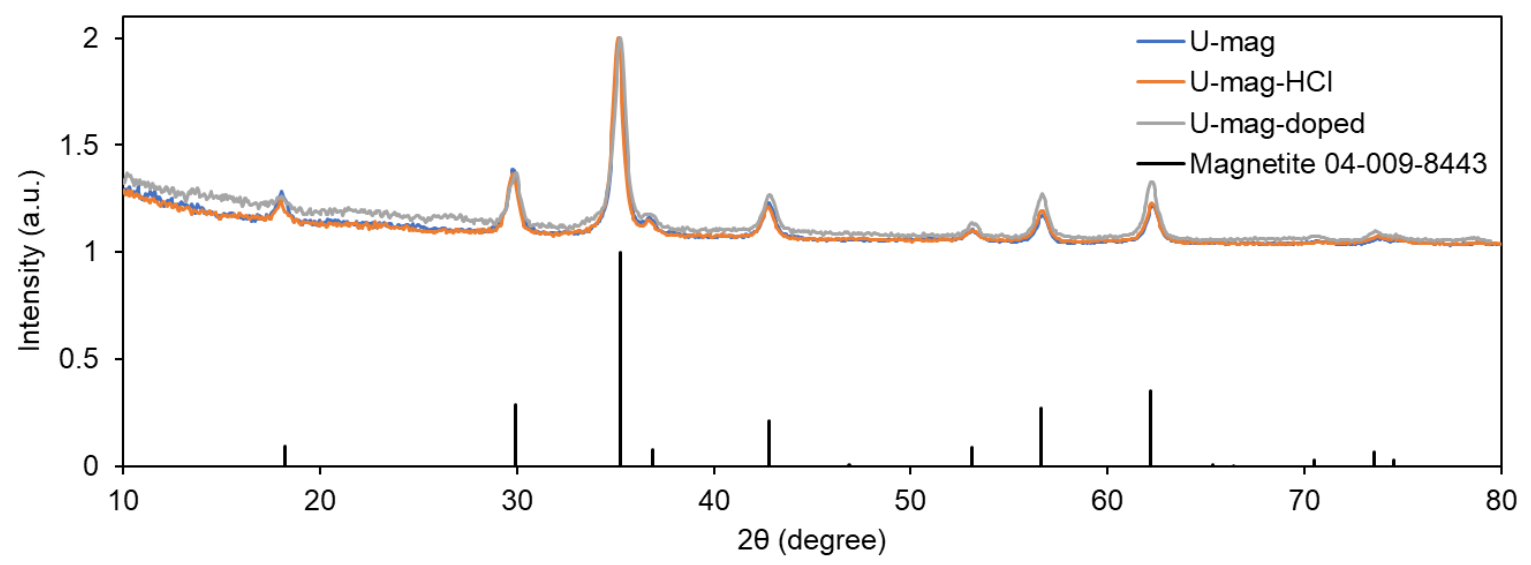

Figure S1. XRD spectra. U-mag, U-mag-HCl and U-mag-doped samples were collected, transferred on zero-background sample holders and mounted on a Panalytical Empyrean X-ray polycrystalline diffractometer, equipped with long-focused $\mathrm{Cu}$ X-ray tube, and Pixcel 1D Xray detector. The patterns were collected in continuous mode between 10 and 80 degrees 2 theta, with the step-size of 0.05 degree. The pattern reduction, as well as the following searchmatching, were performed with HighScore plus v4.9 and PDF4 v2021. ${ }^{11}$ Magnetite reference: ICDD 04-009-8443. 

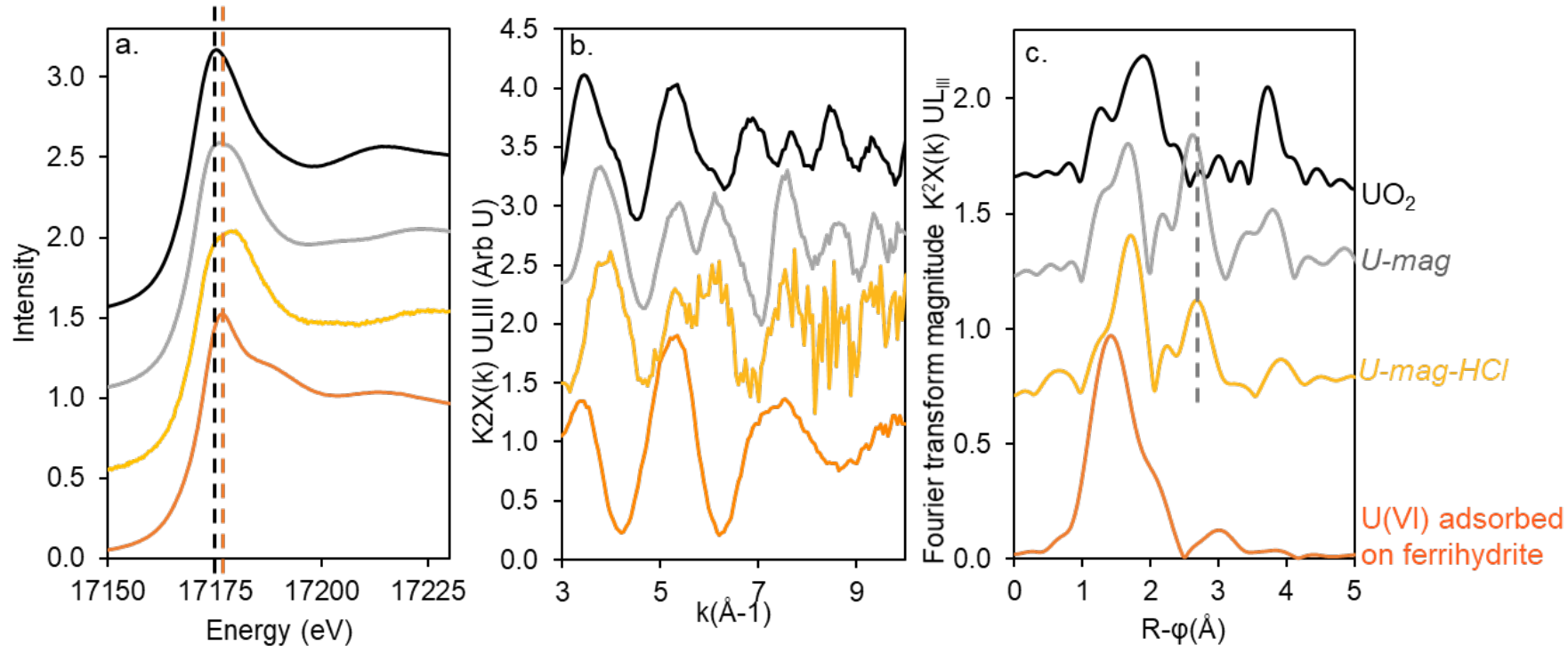

Figure S2. U L $\mathrm{L}_{3}$-edge XAS spectra. (a) U L $\mathrm{L}_{3}$-edge XANES spectra, (b) $\mathrm{k}^{2}$-weighted U $\mathrm{L}_{3}$-edge EXAFS spectra and (c) Fourier Transform of EXAFS spectra for samples $U$-mag and $U$-mag$\mathrm{HCl}$, compared to $\mathrm{UO}_{2}$ and $\mathrm{U}(\mathrm{VI})$ adsorbed on ferrihydrite spectra. The last two spectra were already published in Pan et al. and Stylo et al. ${ }^{12,13}$. Dashed lines in (a) indicate the white line energy position for U(IV) and U(VI) valence states and the dashed line in (c) indicates the UFe pair correlation ${ }^{8,14}$. 
U-mag-doped

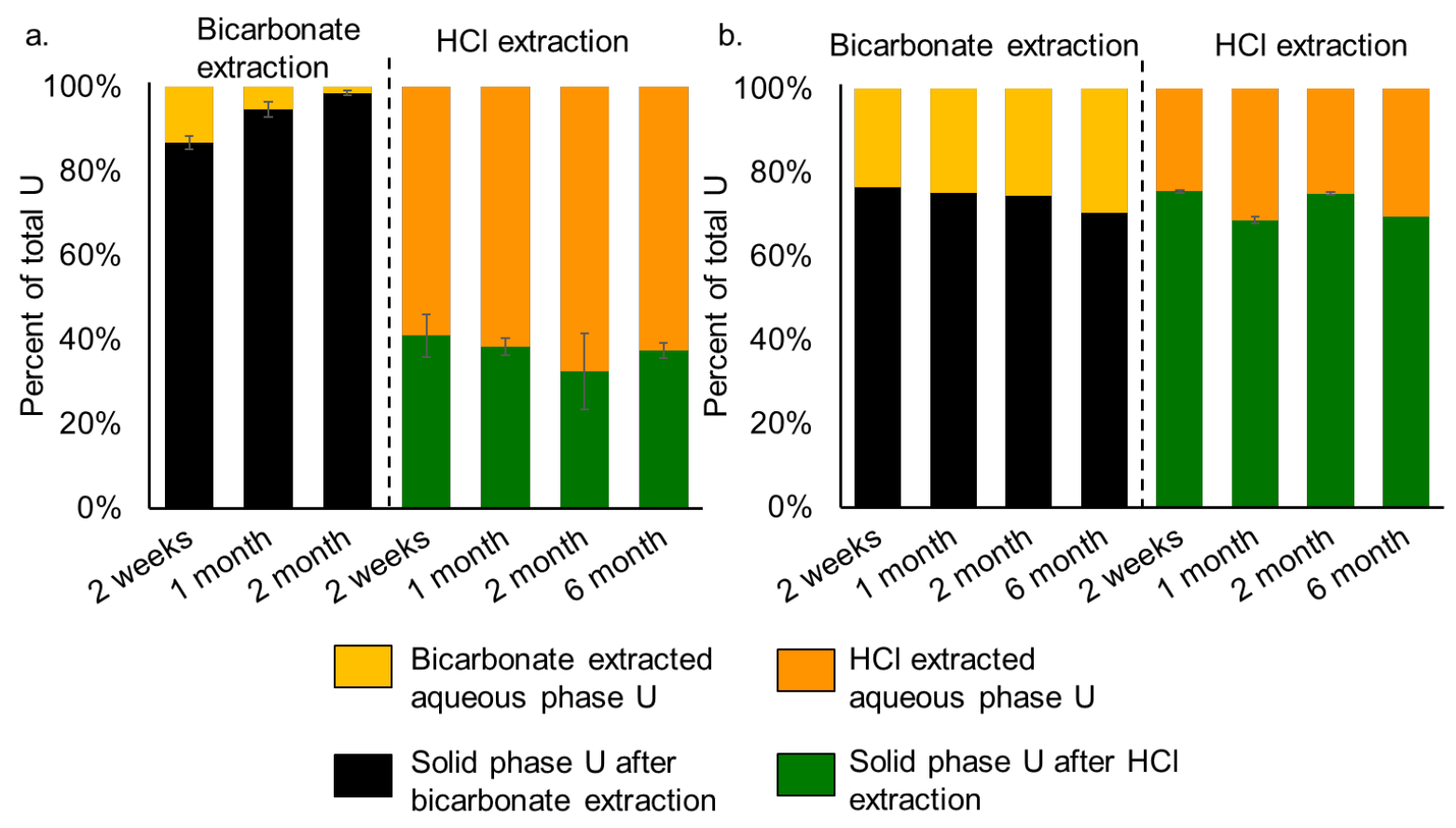

Figure S3. U distribution between solid and aqueous phase after bicarbonate or $\mathrm{HCl}$ extraction. (a) U-mag-doped suspension ( $U$-mag equilibrated with 4.5 and $4 \%$ U(VI) at a mass ratio of $1: 1)$ and (b) U-mag-oxidized suspension (U-mag equilibrated in air). Yellow bars: percentage of $U$ in the bicarbonate extracted aqueous phase; black bars: percentage of $U$ remaining in the solid phase after bicarbonate extraction; orange bars: percentage of $U$ in the HCl-extracted aqueous phase; green bars: percentage of $\mathrm{U}$ in solid phase after the $\mathrm{HCl}$ extraction. Error bars represent the standard deviation from replicates. A bicarbonate extraction was not performed for $U$-mag-doped system at the 6-month time point. 


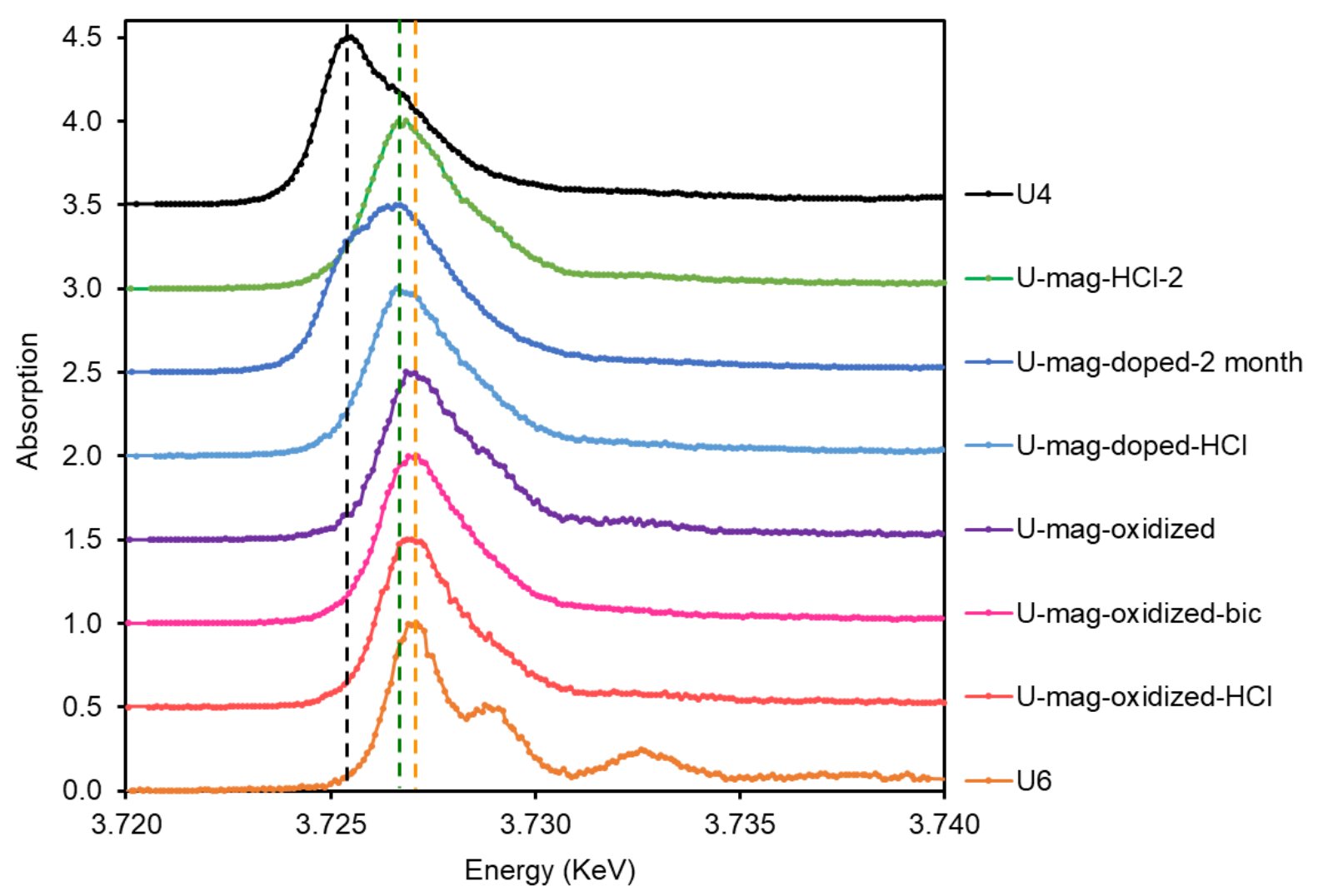

Figure S4. U M4-edge HERFD-XANES spectra for solid-phase samples for a number of conditions (top to bottom): $\mathrm{U}(\mathrm{IV})$ reference $\left(\mathrm{UO}_{2}\right) ; U$-mag treated with $\mathrm{HCl}$; incubation of $U$ mag for 2 months post-amendment with heavy U(VI) isotope (U-mag-doped, 2 month); treatment of that solid phase with $\mathrm{HCl}(U$-mag-doped-HCl); exposure of $U$-mag to ambient condition for 2 months (U-mag-oxidized, 2 month); treatment of that solid phase with bicarbonate solution (U-mag-oxidized-bic); or with $\mathrm{HCl}$ (U-mag-oxidized-HCl); the uranyl(VI) reference as U(VI)-acetate. Dashed lines indicate the white line energy position for U(IV) (black), U(V) (green) and U(VI) (orange) valence states. 


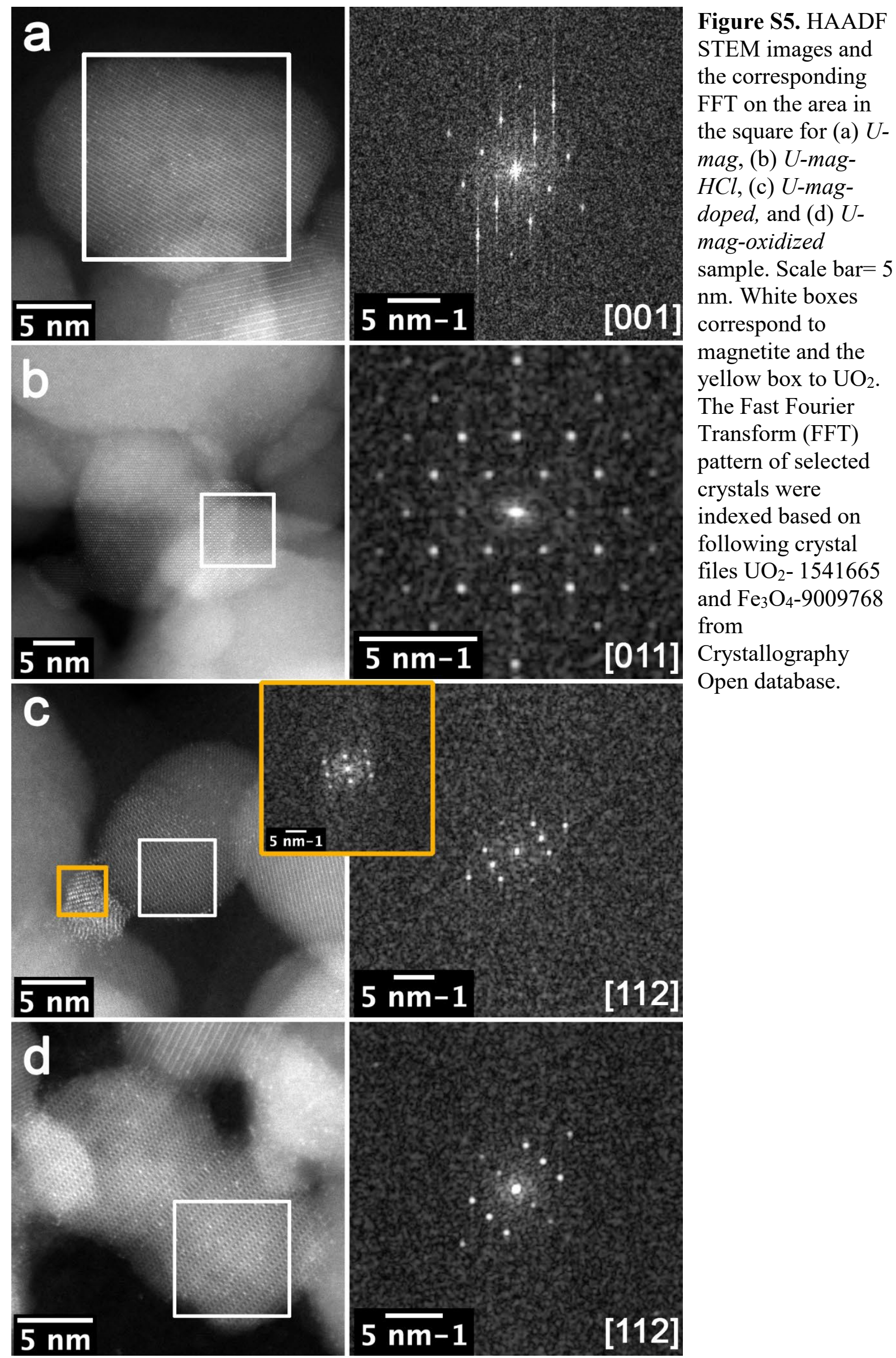




\section{SI reference}

(1) Brennecka, G. A.; Herrmann, A. D.; Algeo, T. J.; Anbar, A. D. Rapid Expansion of Oceanic Anoxia Immediately before the End-Permian Mass Extinction. Proc. Natl. Acad. Sci. U. S. A. 2011, 108 (43), 17631-17634. https://doi.org/10.1073/pnas.1106039108.

(2) Weyer, S.; Anbar, A. D.; Gerdes, A.; Gordon, G. W.; Algeo, T. J.; Boyle, E. A. Natural Fractionation of 238U/235U. Geochim. Cosmochim. Acta 2008, 72 (2), 345359. https://doi.org/10.1016/j.gca.2007.11.012.

(3) Noordmann, J.; Weyer, S.; Montoya-Pino, C.; Dellwig, O.; Neubert, N.; Eckert, S.; Paetzel, M.; Böttcher, M. E. Uranium and Molybdenum Isotope Systematics in Modern Euxinic Basins: Case Studies from the Central Baltic Sea and the Kyllaren Fjord (Norway). Chem. Geol. 2015, 396, 182-195.

https://doi.org/10.1016/j.chemgeo.2014.12.012.

(4) Richter, S.; Eykens, R.; Kühn, H.; Aregbe, Y.; Verbruggen, A.; Weyer, S. New Average Values for the $\mathrm{n}(238 \mathrm{U}) / \mathrm{n}(235 \mathrm{U})$ Isotope Ratios of Natural Uranium Standards. Int. J. Mass Spectrom. 2010, 295 (1-2), 94-97. https://doi.org/10.1016/j.ijms.2010.06.004.

(5) Solé, V. A.; Papillon, E.; Cotte, M.; Walter, P.; Susini, J. A Multiplatform Code for the Analysis of Energy-Dispersive X-Ray Fluorescence Spectra. Spectrochim. Acta Part B At. Spectrosc. 2007, 62 (1), 63-68.

https://doi.org/https://doi.org/10.1016/j.sab.2006.12.002.

(6) Roßberg, A.; Reich, T.; Bernhard, G. Complexation of Uranium(VI) with Protocatechuic Acid-Application of Iterative Transformation Factor Analysis to EXAFS Spectroscopy. Anal. Bioanal. Chem. 2003, 376 (5), 631-638. https://doi.org/10.1007/s00216-003-1963-5.

(7) Rossberg, A.; Ulrich, K.-U.; Weiss, S.; Tsushima, S.; Hiemstra, T.; Scheinost, A. C. Identification of Uranyl Surface Complexes on Ferrihydrite: Advanced EXAFS Data Analysis and CD-MUSIC Modeling. Environ. Sci. Technol. 2009, 43 (5), 1400-1406. https://doi.org/10.1021/es801727w.

(8) Pidchenko, I.; Kvashnina, K. O.; Yokosawa, T.; Finck, N.; Bahl, S.; Schild, D.; Polly, R.; Bohnert, E.; Rossberg, A.; Göttlicher, J.; Dardenne, K.; Rothe, J.; Schäfer, T.; Geckeis, H.; Vitova, T. Uranium Redox Transformations after U(VI) Coprecipitation with Magnetite Nanoparticles. Environ. Sci. Technol. 2017, 51 (4), 2217-2225. https://doi.org/10.1021/acs.est.6b04035.

(9) Ravel, B.; Newville, M. ATHENA, ARTEMIS, HEPHAESTUS: Data Analysis for XRay Absorption Spectroscopy Using IFEFFIT. J. Synchrotron Radiat. 2005, 12 (4), 537-541. https://doi.org/10.1107/S0909049505012719.

(10) Popa, K.; Prieur, D.; Manara, D.; Naji, M.; Vigier, J.-F.; Martin, P. M.; Dieste Blanco, O.; Scheinost, A. C.; Prüßmann, T.; Vitova, T.; Raison, P. E.; Somers, J.; Konings, R. J. M. Further Insights into the Chemistry of the Bi-U-O System. Dalt. Trans. 2016, 45 (18), 7847-7855. https://doi.org/10.1039/C6DT00735J.

(11) The HighScore suite, T. Degen, M. Sadki, E. Bron, U. König, G. Nénert; Powder Diffraction / Volume 29 / Supplement S2 / December 2014, pp S.-S. No Title.

(12) Pan, Z.; Bártová, B.; LaGrange, T.; Butorin, S. M.; Hyatt, N. C.; Stennett, M. C.; Kvashnina, K. O.; Bernier-Latmani, R. Nanoscale Mechanism of UO2 Formation through Uranium Reduction by Magnetite. Nat. Commun. 2020, 11 (1), 1-12. https://doi.org/10.1038/s41467-020-17795-0.

(13) Stylo, M.; Neubert, N.; Wang, Y.; Monga, N.; Romaniello, S. J.; Weyer, S.; BernierLatmani, R. Uranium Isotopes Fingerprint Biotic Reduction. Proc. Natl. Acad. Sci. U. S. A. 2015, 112 (18), 5619-5624. https://doi.org/10.1073/pnas.1421841112. 
(14) Roberts, H. E.; Morris, K.; Law, G. T. W.; Mosselmans, J. F. W.; Bots, P.; Kvashnina, K.; Shaw, S. Uranium(V) Incorporation Mechanisms and Stability in $\mathrm{Fe}(\mathrm{II}) / \mathrm{Fe}(\mathrm{III})$ (Oxyhydr)Oxides. Environ. Sci. Technol. Lett. 2017, 4 (10), 421-426. https://doi.org/10.1021/acs.estlett.7b00348. 